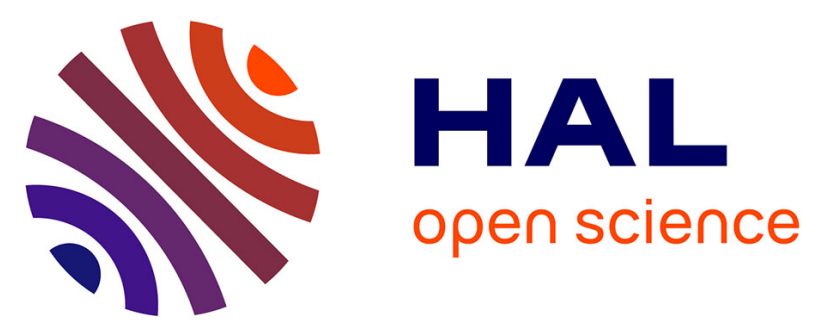

\title{
Flexibilizing Distribution Network Systems via Dynamic Reconfiguration to Support Large-Scale Integration of Variable Energy Sources Using a Genetic Algorithm
}

\author{
Marco Cruz, Desta Z. Fitiwi, Sérgio F. Santos, João Catalão
}

\section{To cite this version:}

Marco Cruz, Desta Z. Fitiwi, Sérgio F. Santos, João Catalão. Flexibilizing Distribution Network Systems via Dynamic Reconfiguration to Support Large-Scale Integration of Variable Energy Sources Using a Genetic Algorithm. 8th Doctoral Conference on Computing, Electrical and Industrial Systems (DoCEIS), May 2017, Costa de Caparica, Portugal. pp.72-80, 10.1007/978-3-319-56077-9_6 . hal01629578

\section{HAL Id: hal-01629578 \\ https://hal.inria.fr/hal-01629578}

Submitted on 6 Nov 2017

HAL is a multi-disciplinary open access archive for the deposit and dissemination of scientific research documents, whether they are published or not. The documents may come from teaching and research institutions in France or abroad, or from public or private research centers.
L'archive ouverte pluridisciplinaire HAL, est destinée au dépôt et à la diffusion de documents scientifiques de niveau recherche, publiés ou non, émanant des établissements d'enseignement et de recherche français ou étrangers, des laboratoires publics ou privés. 


\title{
Flexibilizing Distribution Network Systems via Dynamic Reconfiguration to Support Large-scale Integration of Variable Energy Sources Using a Genetic Algorithm
}

\author{
Marco R. M. Cruz ${ }^{1}$, Desta Z. Fitiwi ${ }^{1}$, Sérgio F. Santos ${ }^{1}$, João P.S. Catalão ${ }^{1,2,3}$ \\ ${ }^{1}$ C-MAST, University of Beira Interior, Covilhã 6201-001, Portugal \\ 2 INESC TEC and the Faculty of Engineering of the University of Porto, Porto 4200-465 \\ ${ }^{3}$ INESC-ID, Instituto Superior Técnico, University of Lisbon, Lisbon 1049-001, Portugal \\ marco.r.m.cruz@gmail.com; destinzed@gmail.com; sdfsantos@ubi.pt; catalao@fe.up.pt;
}

\begin{abstract}
In recent years, the level of variable Renewable Energy Sources (vRESs) integrated in power systems has been increasing steadily. This is driven by a multitude of global and local concerns related to energy security and dependence, climate change, etc. The integration of such energy sources is expected to continue growing in the coming years. Despite their multifaceted benefits, variable energy sources introduce technical challenges mainly because of their intermittent nature, particularly at distribution levels. The flexibility of existing distribution systems should be significantly enhanced to partially reduce the side effects of vRESs. One way to do this is using a dynamic network reconfiguration. Framed in this context, this work presents an optimization problem to investigate the impacts of grid reconfiguration on the level of integration and utilization of vRES power in the system. The developed combinatorial model is solved using a genetic algorithm. A standard IEEE 33node distribution system is employed in the analysis. Simulation results show the capability of network switching in supporting large-scale integration of vRESs in the system while alleviating their side effects. Moreover, the simultaneous consideration of vRES integration and network reconfiguration lead to a better voltage profile, reduced costs and losses in the system.
\end{abstract}

Keywords: Distributed generation, Network reconfiguration, RESs, Genetic Algorithm, Variable Energy Resources.

\section{Introduction}

In recent years, integration of Distributed Generations (DGs) in electric distribution systems has attracted more attention due to various reasons [1]. The purpose of DG is to install small generation plants (mainly of non-conventional energy sources) close to end-users. Because of the growing concerns on climate changes, increased demand for electricity and other reasons, several states are adopting new policies to support the development of "clean" energy resources and address these concerns [2]. 
Nevertheless, dramatically increasing the level of variable Renewable Energy Sources (vRESs) often poses some technical challenges that often undermine the stability and reliability of the system as well as the quality of power delivered to consumers [3]. This is because such intermittent energy sources substantially increase the level of operational variability and unpredictability in distribution network systems, which further complicate the "operation, planning and control" of such systems [1]. This can be addressed by enhancing the flexibility of existing systems. One way to do this is using dynamic distribution system reconfiguration (DSR). A dynamic DSR can considerably enhance the flexibility of the system and improve voltage profiles, thereby, increasing chances of accommodating large-scale vRES power. The DG placement and sizing problem has been widely studied especially in recent years. In relation to this, authors in [4] present a detailed review of existing literature in DG allocation and associated issues. Depending on the size and type of DGs, their integration in distribution network systems may have positive or negative effects. Authors in [4] and [5] employ several techniques to analyze the impact of DGs in electrical systems as a whole. Some researchers resort to ways that can be used to develop appropriate rules for allocating DGs in distribution network systems while minimizing their possible side effects [6]-[10]. In this regard, the most relevant issues that need to be accounted for in DG integration include the network topology, DG capacity and suitable location among others. In the absence of advanced enabling mechanisms such as smart-grids, each connection point in distribution network systems has a maximum DG penetration limit beyond which some of the system performance indicators such as losses and technical issues are undermined [11], [12]. One of the main aims of this work is to develop appropriate tools for optimally integrating variable energy sources so that the quality of power delivered to end-users is enhanced at a minimal possible cost. To this end, an optimization problem is proposed to optimally deploy such resources in distribution systems, and investigate the impacts of grid reconfiguration on the penetration level of vRESs in such systems. The developed model is solved using a genetic algorithm. A standard IEEE 33-node distribution system is employed in the analysis. Hence, one of the main contributions of this work is an improved mathematical model for jointly optimizing distribution network reconfiguration and allocation of RES-based DGs. Another contribution is the quantitative and qualitative analysis made to assess the impacts of network reconfiguration on the penetration and utilization level of intermittent power, and relevant system variables in the distribution system.

\section{Relationship to Smart Systems}

The integration of DGs in electrical distribution network systems (renewable types, in particular) has been gaining momentum since recently. This is driven by a number of factors of technical, economic and environmental nature. Growing concerns related to the increasing demand for electricity, energy security and climate change will further lead to a continuously increasing share of vRESs (such as wind and solar) in the final energy consumption. However, a very high penetration level of such resources results in some technical challenges in the system that may undermine the integrity, stability, 
reliability and quality of power delivered to consumers [1]. This is mainly due to the intermittent nature of such energy sources that substantially increase operational variability and unpredictability in the power production. To deal with such challenges, existing systems should be equipped with new flexibility mechanisms. For example, the deployments of smart-grid technologies are expected to adequately overcome the technical challenges posed by RES-based DGs as a result of the dramatically enhanced system flexibility [1], [13]. In connection to this, a dynamic (and possibly automated) distribution network reconfiguration is one of these technologies that are expected to be rolled out in distribution systems for the same purpose. Distribution System Operators (DSOs) can reap the benefits of automated DSR that along with other smart systems helps to address the challenges of DG sizing and allocation problem [14]. In general, the contribution of the current work to smart systems can be summarized with the following points:

1. DSOs can invest in smart-grid systems that have the capability to automatically switch branches in order to operate the system with reduced costs and improved system stability.

2. After the integration of vRES based DGs, smart systems that have the capability to switch branches can efficiently route RES power generated elsewhere where the demand is low to locations where demand is relatively higher, hence reducing curtailment. All this leads to an enhanced voltage profile and reduced energy losses in the system.

3. Smart grids and isolated systems are often based on vRES technologies. Innovation in smart systems will influence control and operation of these systems, reducing the impact of the associated variability and uncertainty of such DGs. This in turn implies better performances in terms of stability, reliability and quality of the systems. In the near future, isolated systems may operate automatically, without DSO's intervention. And, this can bring fewer concerns for remotely located systems.

\section{Model Formulation}

\subsection{Objective Function}

The main objective of the problem is to minimize the total costs of operation in the system, which is given by (1).

$$
F=\min C_{\mathrm{i}}
$$

where $\mathrm{Ci}$ is the cost of each population, contained in the fitness vector. The formulation of the problem is based on the AC network model. In order to solve the AC optimal power flow problem, MatPower is used. The combinatorics of DSR is handled via a genetic algorithm. Details of the algorithm are presented below.

a) Initialization: In order to set the connected branches, a binary population is assumed. First, populations whose number is equal to the number of links are generated. The generated populations should keep the network radial, given by the number of buses minus the number of generators. The DG sizing problem assumes 
integer values. Hence, a DG chromosome generates integer numbers, representing the size of a DG and with a length equivalent to the number of buses to simultaneously handle the allocation problem. This means that each population has the size and the location information of each DG type.

b) Mutation: Uniform crossover, Boolean mutation for the connected branch is used. At the same time, integer mutation for the DG placement and size is used for new populations based on the best populations.

c) Selection: Tournament selection is used to select the best minimal cost. In tournament selection, $n$ individuals of a population are selected randomly with the same probability. The individual with the greatest fitness among them is selected and passed to an intermediate population. The process ends when the intermediate population is fulfilled. Crossover uses the information in two or more individuals to generate one or more individuals. Mutation can diversify when new information is introduced in the individual, and consequently to the population.

\subsection{Restrictions}

In order to keep the radiality of the network system, one needs to check if the generated population fulfils the following criterion:

$$
N_{\text {closed branches }}=N_{\text {buses }}-N_{\text {generators }}
$$

This condition is applied to check if the criterion is satisfied. This is a necessary condition but not sufficient to obtain a radial topology. It is therefore necessary to verify if all buses in the system are connected. This condition is expressed as follows [15]:

$$
\forall_{X_{i}, X_{j}} \in N, \ni\left\{C_{i} \cup C_{j}\right\}\left(\prod_{k}^{n} Z_{i_{k}} \prod_{k}^{n} Z_{f_{k}}^{n}=1\right)
$$

where $N$ represents the set of nodes in the system; $C_{i} \cup C_{j}$ is the unique path connecting nodes $i$ and $j ; Z_{i_{k}}$ and $Z_{\tilde{f}_{k}}$ refer to the statuses ( 0 or 1$)$ of the $n$ branches in the system that constitute the path $C_{i} \cup C_{j}$; and $k$ is an index of the branches that constitute each path. In addition to the above constraints, the lower and upper limits of system variables such as voltage, current, active and reactive power generation are included.

\subsection{Active and Reactive Power Balances}

The constraint related to the active power balance is enforced using Eq. (4):

$$
g P\left(\theta_{;}, V_{m} ; P_{g}\right)=P_{\text {bus }}\left(\theta ; V_{m}\right)+P_{d}-C_{g} P_{g}=0
$$

Similarly, reactive power balance should be ensured, which is given by (5): 


$$
g Q\left(\theta_{;} V_{m} ; Q_{g}\right)=Q_{b u s}\left(\theta_{;} V_{m}\right)+Q_{d}-C_{g} Q_{g}=0
$$

where $\theta$ and $V_{m}$ refer to the voltage angle and magnitude; $P_{g}$ and $Q_{g}$ are generator injections; $P_{d}$ and $Q_{d}$ : load injections; $C_{g}$ : a matrix whose $\left(i_{i} j\right)^{\text {th }}$ element is 1 if generator $j$ is located at bus $i$ and 0 otherwise.

\section{Tests and Results}

To perform the analysis in this work, a standard 33-bus radial distribution network, taken from [16], is employed. The rated voltage, active and reactive power demand in this system are $12.66 \mathrm{kV}, 3.715 \mathrm{MW}$ and $2.3 \mathrm{MVAr}$, respectively. Further information about this system can be found in [16], [17]. The voltage at any node in the system is allowed to deviate up to a maximum value of $\pm 5 \%$. All DGs are assumed to have a power factor of 0.95 . The costs of the generators at the feeders are given by polynomial functions $C(P)=150+20 P+0.01 P^{2} € / h$. For integrating the DG as a PV bus and add to the cost of the system given by the OPF, one polynomial function was taken into consideration $C(P)=8 P € / h$. For the sake of simplicity, the availability of wind and solar power sources is assumed to be uniform across the nodes in the system. Furthermore, Node 1 is considered as the reference node, and a base power of $100 \mathrm{MVA}$ is used. A total of six cases, designated as Case $i$, are considered in the analysis. Case 1 is the base case; Case 2 considers reconfiguration; Case 3 is a scenario where minimizes only losses. Cases 4,5 and 6 all handle reconfiguration along with DG integration but they differ in that, in Case 4 , the considered DGs are capable of producing active power as well as injecting and absorbing reactive power, Case 5 considers DGs that can only produce active power, and the DGs considered in Case 6 are capable of only producing or consuming reactive power. The variations of system parameters when considering different are analyzed as shown in Table 1. Comparing Case 1 with Case 2 , we see that reconfiguration slightly lowers the total costs and losses. The total cost reduction is about $0.54 \%$. The active and reactive power losses are also reduced by $61.59 \%$ and $17.38 \%$, respectively. In Fig. 1, the voltage profiles of the system after reconfiguration and the base case are shown. Clearly, the positive contribution of reconfiguration to the voltage profiles can be observed. In addition, in Table 1, there is little difference between minimization of losses and minimization of costs, the difference is approximately $0.0057 \%$ for total costs, $0.5147 \%$ for active power losses and $0.5695 \%$ for reactive power losses. In Table 2 , the only difference lies between the opened branches that is 9-11 in Case 2, and 10-11 in Case 3. Only one branch is different, and almost leads to similar fitness function values. There is a small difference and we can conclude that these configurations are minimized but may not be the global optima. Analyzing the results in Table 1 further, there is a significant difference in total costs and in total losses in Cases 4 and 5 compared to the first three cases. The effects of having DGs capable of producing only active or reactive power are also seen in Fig. 2. With active-power-only DGs, we can also have a better voltage profile, not as linear as in Case 4 but significantly better than in the base case. 
Deploying reactive-power-only DGs also has some noticeable impact in systems losses, and voltage profiles. In Case 5, the reduction in total costs is $20.65 \%$ compared with Case 2 and 21.08\% when compared with Case 1. Compared with Case 2 , active and reactive power losses are slashed by $76.22 \%$ and $66.68 \%$, respectively. As in Case 6, there is no big impact in total costs, only $0.87 \%$ when compared with Case 1 but, there is a huge difference in terms of losses. Compared with Case 1, the active and reactive power losses are reduced by $53.04 \%$ and $32.69 \%$, respectively. Although the costs are slightly increased, the benefits of having DGs with this technology are evident with the substantial reduction of losses and improvement in voltage profile. The placement and sizing of DGs may not be optimal because of the solution method. However, there are small differences from one generation type to another, probably indicating the closeness of the solution to the optimal one.

Table 1. Values of relevant system variables corresponding to the different cases.

\begin{tabular}{l|l|l|lr|l|l}
\hline Cases & $\begin{array}{l}\text { Total } \\
\text { Cost } \\
{[\epsilon / \mathrm{h}]}\end{array}$ & $\begin{array}{l}\text { Total Active } \\
\text { Power } \\
\text { Losses } \\
{[\mathrm{MW}]}\end{array}$ & $\begin{array}{l}\text { Total Reactive } \\
\text { Power } \\
{[\text { Mvar }]}\end{array}$ & $\begin{array}{l}\text { Losses installed } \\
\text { DG size } \\
{[\mathrm{MVA}]}\end{array}$ & $\begin{array}{l}\text { Computatio } \\
\text { n time }[\mathrm{s}]\end{array}$ \\
\hline 1 & $\begin{array}{l}228.181 \\
6\end{array}$ & 0.1865 & 0.0999 & 0 & - \\
\hline 2 & $\begin{array}{l}226.946 \\
3\end{array}$ & 0.1249 & 0.0825 & 0 & 24.423398 \\
\hline 3 & $\begin{array}{l}226.959 \\
3\end{array}$ & 0.1256 & 0.0830 & 0 & 27.102581 \\
\hline 4 & $\begin{array}{l}179.738 \\
5\end{array}$ & 0.0023 & 0.0020 & 23 & 32.926209 \\
\hline 5 & $\begin{array}{l}180.074 \\
7\end{array}$ & 0.0443 & 0.0333 & 17 & 39.599780 \\
\hline 6 & $\begin{array}{l}226.195 \\
4\end{array}$ & 0.0876 & 0.0672 & 15 & 34.074488 \\
\hline
\end{tabular}

Table 2. Branches opened and DG location in the 33-bus distribution system

\begin{tabular}{l|l|l}
\hline Cases & Opened branches & DG Bus Location \\
\hline 1 & $21-8 ; 9-15 ; 12-22 ; 18-33 ; 25-29$ & - \\
\hline 2 & $7-8 ; 9-10 ; 14-15 ; 32-33 ; 25-29$ & - \\
\hline 3 & $7-8 ; 10-11 ; 14-15 ; 32-33 ; 25-29$ & - \\
\hline 4 & $7-8 ; 11-12 ; 15-16 ; 21-22 ; 28-29$ & $\begin{array}{l}4 ; 9 ; 16 ; 17 ; 20 ; 22 ; 23 ; 24 ; 26 ; 30 ; 31 ; \\
32\end{array}$ \\
\hline 5 & $6-7 ; 11-12 ; 14-15 ; 26-27 ; 32-33$ & $5 ; 8 ; 12 ; 13 ; 14 ; 17 ; 23 ; 25 ; 28 ; 31 ; 33$ \\
\hline 6 & $7-8 ; 8-9 ; 14-15 ; 28-29 ; 32-33$ & $5 ; 6 ; 13 ; 15 ; 22 ; 24 ; 30 ; 32$ \\
\hline
\end{tabular}




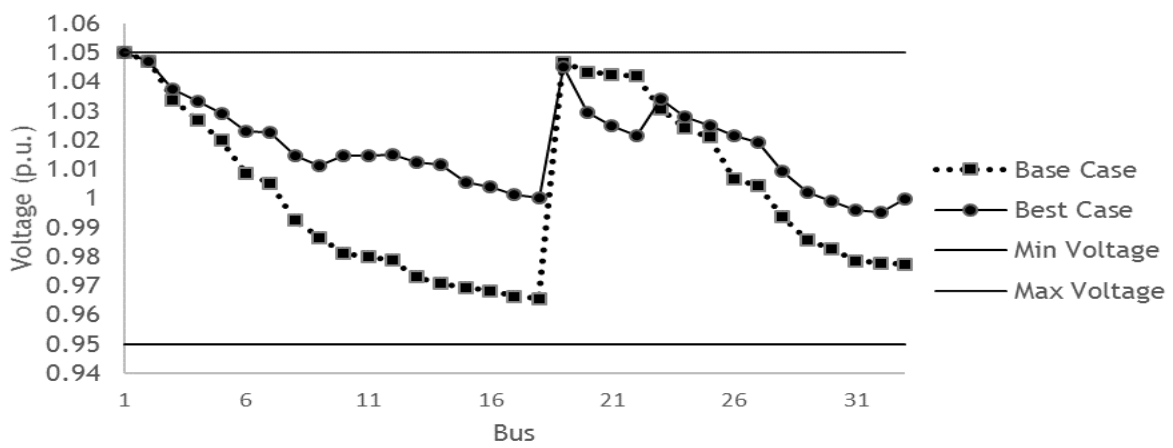

Fig. 1. Voltage profiles corresponding to Cases 1 and 2.

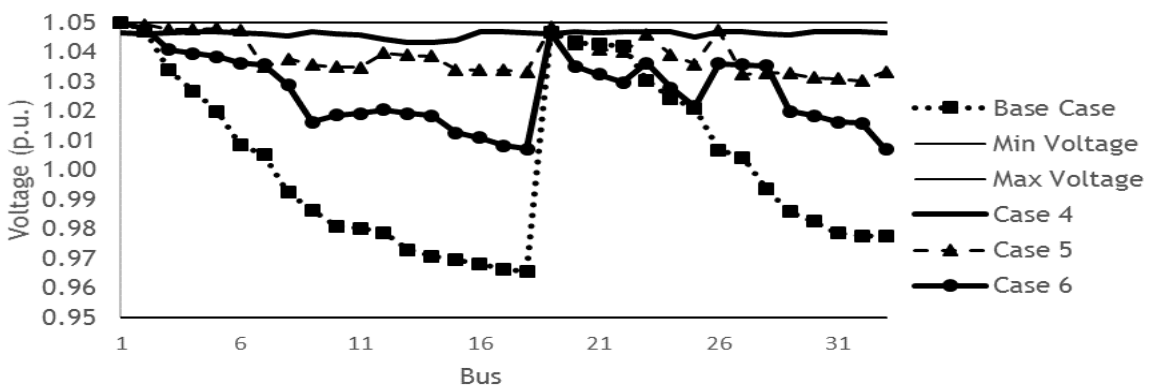

Fig. 2. Voltage profiles corresponding to Cases 1, 4, 5 and 6 .

It seems that there is no connection between Cases 4, 5 and 6 with respect to locating the critical buses to install DG. We can make a connection between Cases 4 and 5 as well as Cases 4 and 6. Recall that Case 4 considers DGs with active and reactive power generation capability while active-power-only and reactive-poweronly DGs are considered in Cases 5 and 6, respectively. Having this in mind, Case 4 and Case 5 seem to have common optimal DG locations including buses 17, 23 and 31. Case 4 and Case 6 also have common "optimal" DG locations such as buses 22, 24,30 and 32. When we look at the demand and at the total installed size of DG, there seems to be a lot of discrepancies among the different cases. The configuration outcome of Case 2 is shown in Fig. 3. Fig. 4 shows the DG location and size corresponding to Cases 4, 5 and 6. Fig. 5 shows the configuration and DG placement outcomes for Case 4. 


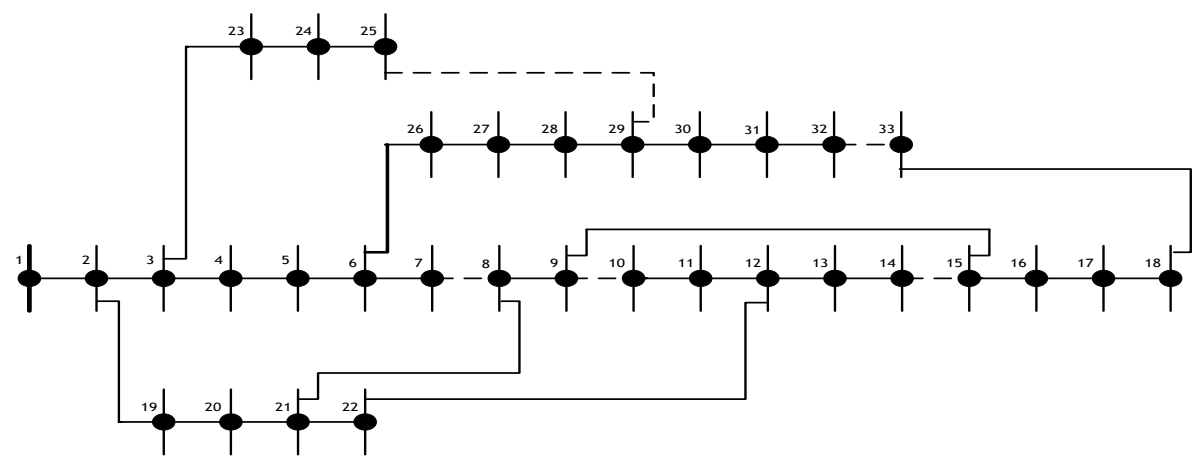

Fig. 3. Network topology after reconfiguration in Case 2

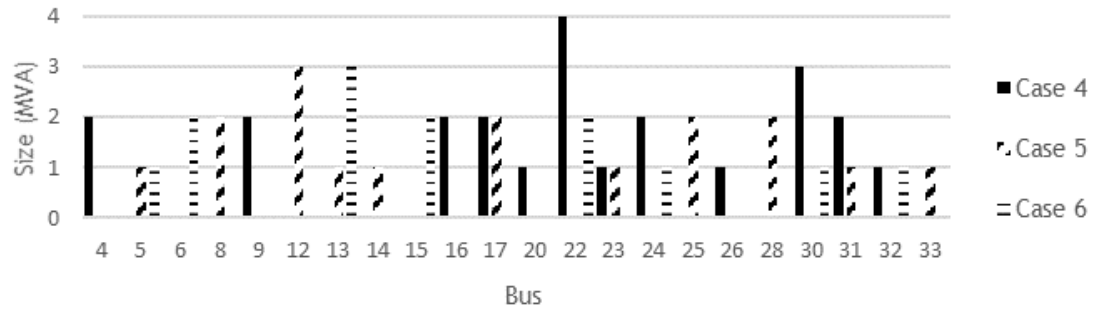

Fig. 4. Location and size of DGs in Cases 4, 5 and 6.

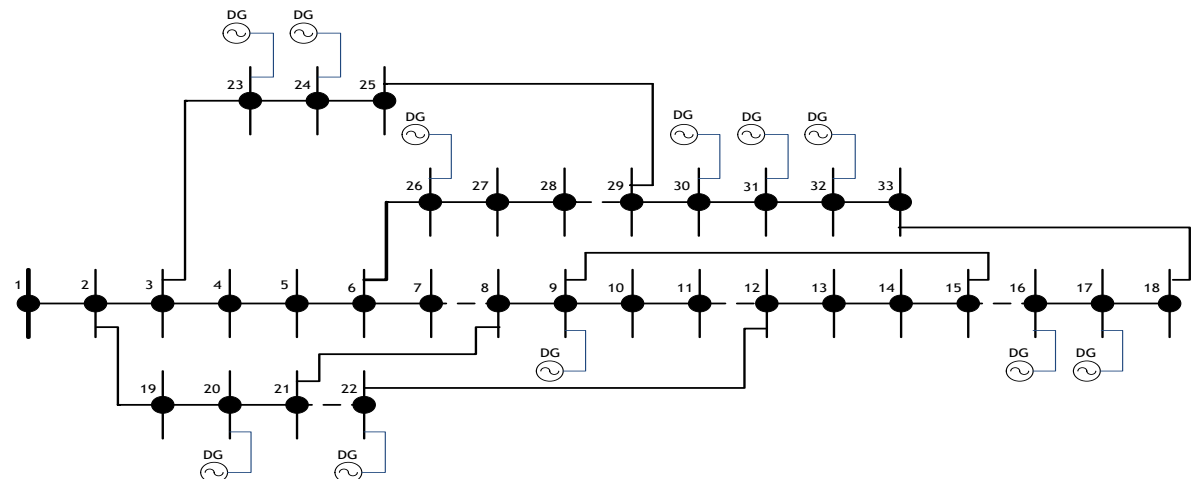

Fig. 5. Network topology and DG placement in Case 4.

\section{Conclusions}

In this work, an improved mathematical model has been developed with the aim of performing quantitative and qualitative analysis with regards to the impacts of 
dynamic network reconfiguration on the penetration and utilization level of variable renewable power and overall system performance. The developed model has the overall cost minimization as an objective, and is based on the most accurate AC network model. A genetic algorithm has been used to efficiently handle the combinatorial nature of the reconfiguration problem. Generally, the outcome of the analysis shows the capability of dynamic network reconfiguration in increasing the penetration and utilization level of vRES as well as improving the overall system performance in terms of enhanced voltage profile, reduced costs and losses.

Acknowledgment. This work was supported by FEDER funds through COMPETE 2020 and by Portuguese funds through FCT, under Projects SAICT-PAC/0004/2015 POCI-01-0145-FEDER-016434, POCI-01-0145-FEDER-006961, $\mathrm{UID} / \mathrm{EEA} / 50014 / 2013$, UID/CEC/50021/2013, and UID/EMS/00151/2013. The research leading to these results has received funding from the EU Seventh Framework Programme FP7/2007-2013 under grant agreement no. 309048.

\section{References}

1 S. F. Santos, D. Z. Fitiwi, M. Shafie-Khah, A. W. Bizuayehu, C. M. P. Cabrita, and J. P. S. Catalao, 'New Multistage and Stochastic Mathematical Model for Maximizing RES Hosting Capacity_Part I: Problem Formulation', IEEE Trans. Sustain. Energy, vol. 8, no. 1, pp. 304-319, Jan. 2017.

2 P. Paliwal, N. P. Patidar, and R. K. Nema, 'Planning of grid integrated distributed generators: A review of technology, objectives and techniques', Renew. Sustain. Energy Rev., vol. 40, pp. 557-570, Dec. 2014.

3 A. Colmenar-Santos, C. Reino-Rio, D. Borge-Diez, and E. Collado-Fernández, 'Distributed generation: A review of factors that can contribute most to achieve a scenario of DG units embedded in the new distribution networks', Renew. Sustain. Energy Rev., vol. 59, pp. 1130-1148, Jun. 2016

4 P. S. Georgilakis and N. D. Hatziargyriou, 'Optimal Distributed Generation Placement in Power Distribution Networks: Models, Methods, and Future Research', IEEE Trans. Power Syst., vol. 28, no. 3, pp. 3420-3428, Aug. 2013.

5 P. Paliwal, N. P. Patidar, and R. K. Nema, 'Planning of grid integrated distributed generators: A review of technology, objectives and techniques', Renew. Sustain. Energy Rev., vol. 40, pp. 557-570, Dec. 2014.

6 D. Q. Hung, N. Mithulananthan, and R. C. Bansal, 'An optimal investment planning framework for multiple distributed generation units in industrial distribution systems', Appl. Energy, vol. 124, pp. 62-72, Jul. 2014.

7 F. S. Abu-Mouti and M. E. El-Hawary, 'Heuristic curve-fitted technique for distributed generation optimisation in radial distribution feeder systems', IET Gener. Transm. Distrib., vol. 5, no. 2, p. 172, 2011.

8 B. C. Pal and R. A. Jabr, 'Ordinal optimisation approach for locating and sizing of distributed generation', IET Gener. Transm. Distrib., vol. 3, no. 8, pp. 713-723, Aug. 2009.

9 R. S. Maciel, M. Rosa, V. Miranda, and A. Padilha-Feltrin, 'Multi-objective evolutionary particle swarm optimization in the assessment of the impact of distributed generation', Electr. Power Syst. Res., vol. 89, pp. 100-108, Aug. 2012. 
10 K. Vinothkumar and M. P. Selvan, 'Fuzzy Embedded Genetic Algorithm Method for Distributed Generation Planning', Electr. Power Compon. Syst., vol. 39, no. 4, pp. 346-366, Feb. 2011.

$11 \mathrm{~F}$. Ugranlı and E. Karatepe, 'Convergence of rule-of-thumb sizing and allocating rules of distributed generation in meshed power networks', Renew. Sustain. Energy Rev., vol. 16, no. 1, pp. 582-590, Jan. 2012.

12 V. V. S. N. Murty and A. Kumar, 'Optimal placement of DG in radial distribution systems based on new voltage stability index under load growth', Int. J. Electr. Power Energy Syst., vol. 69, pp. 246-256, Jul. 2015.

$13 \mathrm{Y}$. Ma, X. Tong, X. Zhou, and Z. Gao, 'The review of smart distribution grid', in Mechatronics and Automation (ICMA), 2016 IEEE International Conference on, 2016, pp. 154-158.

14 X. Zhou, H. Cui, Y. Ma, and Z. Gao, 'Research review on smart distribution grid', in Mechatronics and Automation (ICMA), 2016 IEEE International Conference on, 2016, pp. $575-580$.

15 S. Hayfa, K. Omar, and H. A. Hsan, 'Optimal Power Distribution System Reconfiguration using Genetic Algorithm', presented at the 16th international conference on Sciences and Techniques of Automatic control \& computer engineering, Monastir, Tunisia, 2015.

16 M. R. M. Cruz, 'Benefits of Coordinating Distribution Network Reconfiguration with Distributed Generation and Energy Storage Systems', Universidade do Porto, 2016.

17 M. R. M. Cruz, D. Z. Fitiwi, S. F. Santos, and J. P. S. Catalão, 'Influence of Distributed Storage Systems and Network Switching/Reinforcement on RES-based DG Integration Level', presented at the 2016 13th International Conference on the European Energy Market (EEM), OPorto, 2016. 